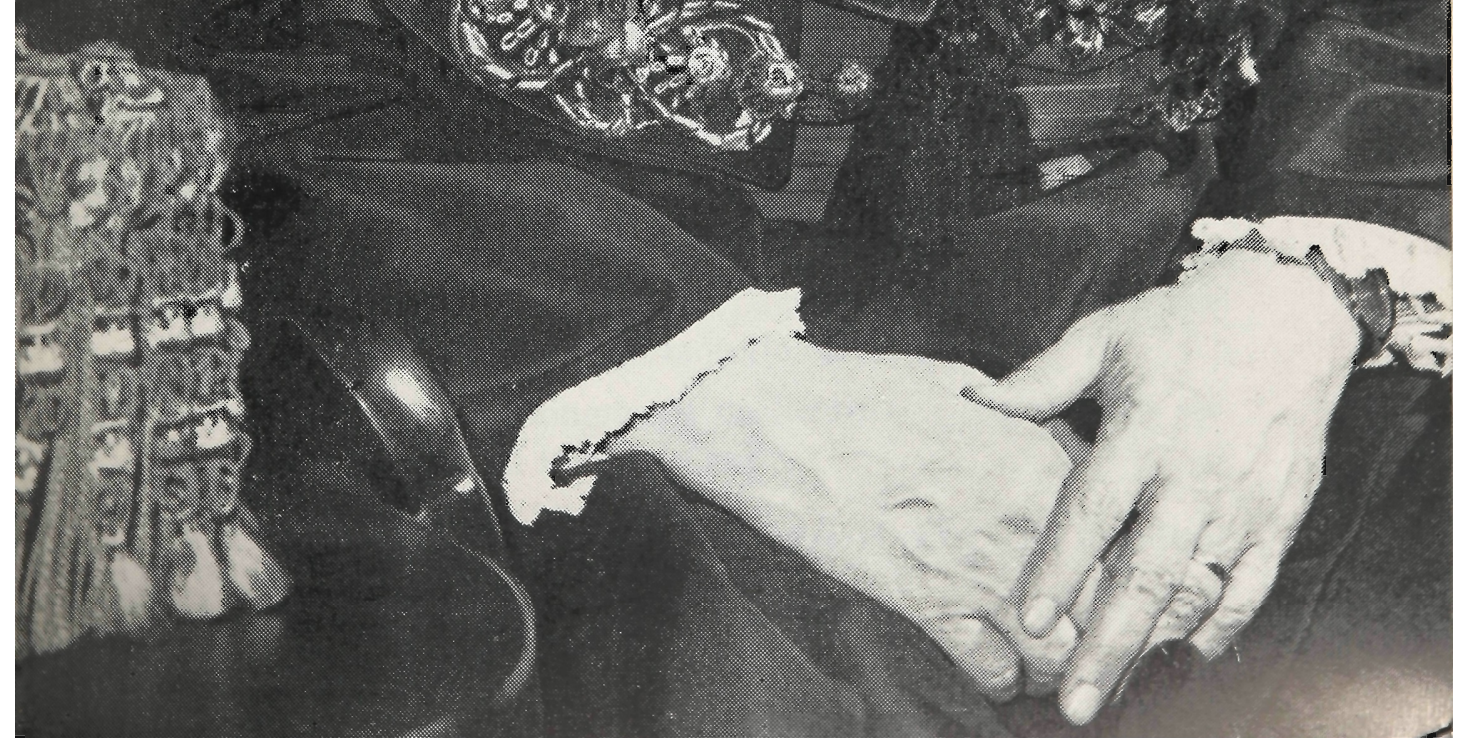


Professor Dr. Celso Neves, Titular de Direito Processual Civil. 


\section{Celso Neves, Titular de Direito Processual Civil.}

\section{A Redação.}

Dr. Celso Neves, novo titular de Direito Processual Civil, filho do Sr. José dos Santos Neves e de D. Dulce Breves Neves, nasceu em São Paulo, aos 24 de setembro de 1913.

Fez os estudos primários no Colégio Progresso Brasileiro, depois na Escola Americana, cumprindo o curso ginasial no Colégio Oswaldo Cruz, nesta capital.

Em 1939 bacharelou-se em Ciências Jurídicas e Sociais, pela Faculdade de Direito da Universidade de São Paulo.

Eleito para membro efetivo do Instituto dos Advogados de São Paulo, em 4 de agosto de 1949, tomou posse em 9 de dezembro daquele ano.

Fazendo parte do Conselho da Ordem dos Advogados do Brasil - Secção de São Paulo - por vários biênios, foi integrar comissões examinadoras de ingresso na magistratura, relativas aos $126 .^{\circ}, 129 .^{\circ}, 130 .^{\circ}, 131$ e $132 .^{\circ}$ concursos.

Participou de comissões de concurso para o cargo de Juiz do Trabalho Substituto. Foi membro efetivo do Tribunal Regional Eleitoral, na classe de jurista, de 15 de fevereiro de 1957 a 14 de abril de 1961, data em que concluía o segundo biênio nessas funções. Em várias oportunidades, i. e., em fevereiro de 1957, setembro de 1958 e abril de 1967, foi indicado pelo Quinto Constitucional para a vaga de Juiz do Tribunal de Alçada Civil do Estado de São Paulo.

Participou de Congressos nacionais e internacionais sobre a matéria de sua especialidade. 
Em 1958 concorreu à cátedra de Direito Judiciário Civil, vaga com o falecimento de Gabriel José Rodrigues de Rezende Filho, apresentando a tese Arrematação de Real a Real. Classificado em 2. ${ }^{\circ}$ lugar, obteve a livre docência da matéria.

Como assistente do professor Dr. Alfredo Buzaid, catedrático de Direito Processual Civil, regeu um de seus cursos e substituiu S. Excelência em seus impedimentos, em 1960, 1963 e de setembro de 1968 a dezembro de 1971.

Com a tese Contribuição ao Estudo da Coisa Julgada Civil, concorreu à titularidade de Direito Processual Civil, vaga em decorrência da aposentadoria do Professor Luís Eulalio de Bueno Vidigal. Aprovado, por unânimidade, em todas as provas, foi nomeado para o cargo do qual tomou posse a $1 .^{\circ}$ de março deste ano.

\section{Bibliografia.}

Além das dissertações de concurso, o Professor Celso Neves publicou os seguintes trabalhos:

1. Desapropriação por Utilidadei Pública, 1942.

2. Direito Real de Hipoteca, 1943.

3. Código de Minas e Constituição, 1948.

4. Ação "Quanti Minoris", 1949.

5. Mandado de Segurança 44.791. 1949.

6. Um Caso Invulgar de Mandado de Segurança, 1959.

7. Ainda uma Vez o Caso de Invulgar Mandado de Segurança, 1959.

8. Em Defesa do Ministério Público do Estado de São Paulo, 1959.

9. Idem, em Aditamento, 1960.

10. Um Mandado de Segurança Absono e Inconseqüente, 1960.

11. A Competência do Juizo Cível, 1961.

12. Um Mandado de Segurança sobre "Controversia Facti", 1961.

13. Agravo de Instrumento 106.004, 1962. 
14. Supremacia da Disciplina Constitucional do Recurso Extraordinário Inexceptuável nos Casos de Revista em que Haja Decisão da Última Instância, 1963.

15. O Dever Estatal de Reparar o Dano, 1967.

16. Uma Possessória Armada para Conquista de Posse Alheia, 1969.

Pareceres, Artigos e Comentários Publicados:

1. Parecer sobre Ação Rescisória, 1956.

2. Defesa do Projeto de Estatuto da Ordem dos Advogados do Brasil, 1956.

3. Parecer sobre gestão de negócios, 1957.

4. Parecer sobre Cumulação Objetiva em Ação Rescisória, 1957.

5. Reflexões sobre a Reconvenção nas Ações de Desquite e Anulação de Casamento, 1960.

6. A Sentença como Título Executório, 1962.

7. A Propósito da Limitação Objetiva de Ação Incidental de Atentado, 1962.

8. Reflexões sobre a Coisa Julgada em Mandado de Segurança, 1966.

9. Parecer sobre Correção Monetária em Desapropriaçăo, 1966.

10. Parecer sobre Prova na Reivindicação.

11. Comentário sobre Correção Monetária, 1969.

Pareceres não Publicados:

1. Os atos jurisdicionais e a inconstitucionalidade das leis, em mandados de segurança, 1962.

2. Preferência do Locatário, 1964.

3 F'ormalidades para Extinção das Fundações, 1965.

4. Disciplina da elaboração legislativa das Câmaras Municipais, 1966.

5. A propósito de suposta inelegibilidade de Secretários de Estado, 1966.

6. Purgação da Mora em Ações de Despejo, 1967.

7. Decisão Apelável em Inventario, 1967.

8. Despejo e Consignação - Conexão, 1968.

9. Interpretação Contratual, 1968.

10. Eficácia de Liquidação procedida perante a Justiça do Trabalho, para fundamentar pedido de falência, 1972. 


\section{o novo professor titular toma posse do cargo.}

A $1 .^{\circ}$ de março deste ano, reuniu-se a Congregação de professores no salão nobre para, solenemente, dar posse do cargo de professor titular de Direito Processual Civil ao Dr. Celso Neves e inaugurar os cursos jurídicos de 1972.

Presidindo à mesa, o Magnífico Reitor da Universidade, professor Miguel Reale, designou os professores Antônio Ferreira Cesarino Junior, Canuto Mendes de Almeida e Goffredo Telles Junior para introduzir na doutoral o novo titular.

Após a leitura do termo de posse e assinatura da ata pelos professores presentes, foi dada a palavra ao Dr. Sílvio Rodrigues que, em nome da Congregação, saudou o professor Celso Neves; referindo-se à rica personalidade do eminente colega e amigo, salientou suas excepcionais qualidades de jurista e mestre. Em seguida o novo titular proferiu o discurso de posse, rememorando etapas de sua vida acadêmica e agradecendo a saudação recebida.

Terminado o discurso de posse o Magnífico Reitor, presidente da mesa, congratulou-se com o Dr. Celso Neves, em nome da Universidade e fez considerações sobre o "curriculum" jurídico baixado pelo Conselho Federal da Educação, responsabilizando a Faculdade pela sua análise e aplicação. Referiu-se, também, à inevitável revolução da ordem jurídica, decorrente da transformação do mundo contemporâneo pela expansão tecnológica, que se projeta nas estruturas básicas do Direito. Conclamou a Faculdade a ser o ponto de partida da "grande revolução", pois "quanto mais uma casa tem raízes nos tempos, mais tem responsabilidade para o futuro", disse o mestre, e deu a palavra ao professor Manoel Gonçalves Ferreira Filho que proferiu a aula inaugural de 1972, sob o título O Modelo Político na Constituição Vigente, publicada na secção de conferências deste volume. Publicam-se, a seguir, o discurso de saudação do professor Sílvio Rodrigues e o de posse do professor Celso Neves. 


\section{Professor Sílvio Rodrigues saúda o novo titular.}

Ao assomar a tribuna desta casa, para saudar o eminente colega professor Celso Neves, no dia em que Sua Excelência toma posse da cadeira de Direito Processual Civil, por ele conquistada em brilhante concurso, meu coração se enche de júbilo, não só pela afeição que dedica ao novo titular, como pelo amor que vota a esta Academia.

Sendo colega de turma de Sua Excelência, acostumei-me a estimá-lo desde os bancos acadêmicos. $\mathrm{E}$ juntos, tenho certeza, começamos a sentir que este velho Convento Franciscano era o nosso segundo domicílio, para onde, se aprouvesse à Providência Divina, nos iríamos encaminhar num futuro remoto. Acredito que tal sina já era a nossa, desde os velhos tempos em que trançávamos por estes vetustos e misteriosos corredores cenobitas, embora sentíssemos pudor de alçar tão alto nossos olhos.

Neste instante, contudo, em que a bondade do Sr. Diretor elegeu-me para receber, em nome da Egrégia Congregação, o meu colega de ontem, e vendo nossos sonhos realizados minha alegria é realmente inescondível. Seja benvindo, na cátedra, querido amigo Celso Neves.

Se quisesse analisar com muita minúcia a personalidade de nosso novo colega, certamente careceria de tempo, porque, ao lado do homem, que é um cavalheiro do maior refinamento e da maior bondade, encontramos a figura respeitável do advogado que se põe em plano paralelo a do consagrado jurista. Para não me deter nos outros ângulos de sua encantadora personalidade, peço venia para acentuar esses três.

Ingressando no curso de bacharelando no ano de 1935, Celso Neves distinguiu-se logo, não só como estudante exemplar, mas igualmente como rapaz ponderado, extremamente bem educado, amigo de todos os colegas, por todos respeitado, pela elegância de seu gesto, pela permanente afabilidade, 
pela sabedoria de seus juízos. Jamais conheci, nestes trinta e tantos anos de convívio, alguém que o não estimasse, nem ouvi qualquer palavra a seu respeito que não fosse encomiástica. Chefe de família dos mais respeitáveis, pai extremoso, amante das letras e das artes, de palavra fácil e elegante, é um exemplo de que a arte da conversa, continua viva e é imorredoura.

Onde a figura humana de Celso Neves se projeta de maneira marcada é quando enverga ele as vestes do advogado. Mal saído da escola enceta a carreira profissional, que por força de seu talento, o conduziu ao absoluto sucesso. Sua inteligência, seu bom senso, aliados a uma enorme cultura, abriram-lhe o lugar que merecia, e, sua banca, até hoje, é das de maior renome.

Todavia não cuidou apenas de seu interesse pessoal e a participação de Celso Neves nas organizações de classe revelou o altruismo de seu comportamento. Foi por longo tempo, Conselheiro da Ordem dos Advogados, e, há mais de 20 anos é membro do Instituto dos Advogados.

Por meia dúzia de vezes, indicado pela Ordem dos Advogados, foi membro da Comissão Examinadora em concursos para provimento do cargo de Juiz Substituto, honraria só deferida a advogados de inegável saber. De outra feita foi examinador em concurso para provimento do cargo de Juiz do Trabalho. Durante dois biênios serviu como Juiz Efetivo do Tribunal Regional Eleitoral, representando a classe dos juristas. E, em 1957, foi indicado para a vaga de Juiz do Tribunal de Alçada, pelo quinto Constitucional.

Todos esses galardões foram obtidos pelo advogado Celso Neves, antes de adquirir o título de livre docente, por ele só conquistado nesta sala, no ano de 1958.

Nessa ocasião, em que o bacharel Celso Neves já adquirira destacada posição no meio jurídico-brasileiro, é que nasce o professor. 
Em memorável concurso, realizado em 1958, obtém Celso Neves a livre-docência, nesta Academia, apresentando formosa monografia sobre a Arrematação de Real a Real, aprovada unanimemente por seus examinadores.

Logo a seguir passou a servir no corpo docente desta casa, de início assistindo nosso ilustre colega prof. Alfredo BuZAID, logo mais, e já em 1960, regendo, esporadicamente, a cadeira daquele ilustre mestre. Entretanto, a partir de setembro de 1968, em virtude de impedimento do catedrático, Celso Neves passava a reger ininterruptamente, turmas nesta Escola.

Gastei tantos adjetivos para enaltecer a pessoa do homem e a do advogado, que me encontro em dificuldades, dada a pobreza de meu vocabulário, em encontrar outros qualificativos mais veementes, para elogiar a figura do professor. Acho, entretanto, que o maior elogio que se pode fazer a um docente é dizê-lo cumpridor devotado de seu dever.

A nós, que militamos no ensino, que temos o extraordinário privilégio de um convívio diuturno com a mocidade, impõe-se uma obrigação inafastável. E, a meu ver, a de não decepcionar a juventude. $\mathrm{E}$ a melhor maneira de corresponder à expectativa depositada pelo aluno no professor é a de executar a tarefa que se nos impuzemos, diligente e ardorosamente. Sei que essa foi a senda escolhida pelo eminente colega que hoje recebemos.

Professor extremamente assíduo, não creio que tenha, a não ser em casos excepcionais, deixado uma centena de estudantes a esperá-lo, sem que estes lhes escutassem os passos, ao tocar da sineta. Didata dos mais completos, sua linguagem é simples e seu verbo fácil, a demonstrar que a ciência que ensina é acessível até mesmo aos não especialistas. Convencido de que para ensinar é mister antes de mais nada saber o que se vai dizer, jamais entrou na sala sem haver preparado sua preleção. $E$ os estudantes, vendo-lhe a dedicação e certos de que o mestre domina a matéria que ensina, votam-lhe um respei- 
to que só dedicam aos entes que admiram. Todavia, sua severidade não se divorcia de uma transbordante bondade, e os alunos que o olham com reverência, o estimam como um amigo maior.

Sua obra jurídica, espalhada em livros, pareceres, artigos, é extremamente vasta. A coroá-la, entretanto, não posso omitir referência à preciosa monografia, com que conquistou a cátedra, Contribuição ao Estudo da Coisa Julgada Civil que se tornou desde logo obra clássica sobre o tema e revela um trabalho de pesquisa e de reflexão de tamanho alcance que todos os seus examinadores não se cansaram de exaltar.

Ao encerrar esta minha saudação ao eminente processualista, o que faço em nome dos Professores da Faculdade de Direito de São Paulo, quero assegurar-lhe, Dr. Celso Neves, de que esta Casa sente-se enriquecida pelo ingresso definitivo de $V$ Excelência em sua Congregação e orgulhosa por contar com nome tão ilustre entre os seus titulares. Ao meu querido colega de bancos escolares, ao meu amigo Celso Neves, falando em nome próprio, eu repito, com o coração na mão e lágrimas nos olhos, sede benvindo nesta casa, meu velho companheiro.

\section{Discurso de posse do professor Celso Neves.}

Treze anos se passaram desde que, como livre-docente, voltei a esta Faculdade, d'onde saira, dezenove anos antes, bacharel em ciências jurídicas e sociais. Desde então, tocado pela magia das tradições desta Casa, mantive, sempre, a candeia sobre o velador, na esperança de, um dia, formar na doutoral, para ser um dentre os eleitos - embora o menor deles - que, dia a dia, aqui realizam o milagre da eucaristia, em nome daquele mesmo ideal que transformou a tranquila São Paulo dos Campos de Piratininga na buliçoșa sede de um dos dois cursos jurídicos que primeiro se instalaram no Brasil.

Nesses treze anos, observei com unção as regras da Or- 
dem, assíduo às orações matinais, fiel aos serviços vespertinos, constante nas celebrações a que a noite acrescentava o sabor das horas prolongadas e o mistério da consumação dos tempos. Sem rumor - porque o noviciado, na sua essência, tem a marca dó silêncio com que o espírito, voltado sobre si mesmo, procura acomodar-se ao compasso diuturno das meditações nesses treze anos, jamais dissimulei a minha própria verdade, cєrto de que só ela, pela medida da minha vocação, poderia abrir-me, ou fechar-me as portas deste monastério.

Já muito antes, na constância das vigílias, procurava armar o meu espírito para a arremetida a estes contrafortes, mais avantajados à medida que passos temerosos me aproximavam do seu sopé aladeirado e sombrio. Vinha-me à mente, nessa caminhada solitária, a conquista de Santarém aos sarracenos e a emprêsa a que me dispunha parecia-me ainda de mais remoto alcance. Se Afonso I se convencera de que o assédio tresloucado não era para se "o levar à escalada vista", mas "à luz duvidosa da noite", aqui o cometimento não poderia ser à sorrelfa, a golpes mudos de punhal. Era de preceito a justa aberta, corpo exposto ao entrevero, para vencer ou morrer, segundo o merecimento que tivesse.

Saltear o cimo da montanha, sem um Mem Ramires para assinalar o atalho mais seguro, sem um MARTiм Монав para solerte rutura de tréguas, era ousadia que só um encantamento poderia suscitar. Lá de cima, a visão do terreno era perfeita, e, nele, a pequenez do ousado haveria de intrigar a guarda castelã. Por fim, deu-se o combate desigual em que, acantonado por cavaleiros de lança e chuço, o peão cuidou de não ter varado o seu frágil arnês. $\mathrm{O}$ esforço desmedido valeulhe a trégua que lhe concederam e a escolha para a vigília d'armas, antes da sagração maior.

Foi assim que me vi livre-docente, em 1958, por emprazamento desse amigo incomparável que é AlFREDo BuzAID, a quem devo, primordialmente, a consagração deste momento. Em verdade, foi ele que, já catedrático, exigiu de mim 
viesse disputar a vaga aberta com o inesperado falecimento daquele eminente e saudoso mestre que foi Gabriel José Rodrigues de Rezende Filho, compelindo-me a uma inscrição que outro objetivo não teve senão o de uma classificação secundária que muito me honraria, porque os méritos de MoACYr Amaral Santos, concorrente natural ao posto, deixavam entrever a sua ascensão à cátedra.

Festejei a vitória desse ilustre professor com a mesma alegria com que recebi o dignificante segundo lugar que me atribuiu a banca examinadora, presidida por esse mestre primoroso que é Luiz Eulálio de Bueno Vidigal e integrada pelos eminentes professores Alfredo Buzaid, Mário Guimarães de Souza, Galeno lacerda e Hélio Bastos Tornaghi.

De uma circunstância desse concurso lembro-me sempre. Por ocasião da defesa de tese, após as argüições feitas por Alfredo Buzaid e HÉlio Tornaghi, o presidente da banca examinadora, Prof. Luiz Eulálio de Bueno Vidigal, suspendeu os trabalhos por quinze minutos. Ainda atordoado pelos embates da prova, levantei-me para recolher-me à Secretaria e já me aprestava para deixar este salão quando um dos catedráticos que formavam na doutoral veio em minha direção, cumprimentando-me, generosamente, pela minha atuação. Era José Pinto Antunes que, com esse gesto - a seguir imitado por outros também eminentes professores - deu ao candidato de então um alento de extraordinária oportunidade.

Terminado o concurso, sobre o velador mantive a minha candeia.

Enriquecido com as inestimáveis contribuições de VIDIGal, Buzaid e Amaral Santos - para só aludir aos catedráticos da matéria nesta Faculdade - o Direito Judiciário Civil - como então se designava a nossa disciplina - atingia, entre nós, maturidade tal que tornava praticamente incompossível com isso uma coadjuvação condigna dos livre-docentes.

Quanto a mim, maior circunspecção se impunha, por- 
que BuZAid cedera-me não só uma de suas regências mas honrara-me, ainda, com a minha indicação para seu assistente. Partilhando comigo, generosamente, as dignidades de sua cátedra, num despreendimento que dá bem a medida de sua grandeza, distinguia-me o consagrado mestre com uma confiança que era imperioso não fosse desmerecida.

A esse gesto - em si bastante para aturdir-me, na inexperiência dos meus primeiros passos de noviciado - procurei corresponder com tresdobrada dedicação e multiplicado empenho. E se não me comportei com brilho, na nobilitante missão, não poupei esforços para merecer a confiança do mestre e não comprometer as esperanças do amigo. Jamais, nestes treze anos em que, como livre-docente, tive o privilégio de reger cursos nesta Faculdade, qualquer desentendimento me separou de meus alunos. Antes, desde a primeira turma que lecionei, entre eles fiz amigos que muito prezo e que me têm proporcionado grandes alegrias. Respeitando-os sempre, recebi deles o nobre respeito dos que não vergam em mesuras preconcebidas. Procurei cumprir, com a maior gravidade e exação, os meus deveres de professor, confiando em que meus alunos fizessem o mesmo. Não raro, alguns sobreexcederam as minhas expectativas. Filho e neto de educadores, regozijo-me em Deus por ter-me conferido esse privilégio de entender e ser entendido por meus discípulos.

A aposentadoria do eminente Professor Luiz Eulálıo DE Bueno Vidigal, não obstante os empenhos da douta Congregação no sentido de uma reversão que todos nós desejávamos, acabou por determinar a realização de novo concurso, a que não me poderia escusar, senão por outros motivos, pelo menos para justificar a atitude daqueles que, durante a livredocência, em mim haviam confiado. Presidiu a banca examinadora o eminente Professor Joaguim Canuto Mendes de AlmEIDA, integrando-a, mais, os doutos professores MoACYr Amaral Santos, Egas Dantas Moniz de Aragão, Alcides Mendonça lima e Celso Agrícola Barbi. 
Indicado, após as provas, à unânimidade, para o provimento da vaga - com aval da douta Congregação presidida pelo Diretor da Faculdade, Professor José Pinto Antunes para ela fui nomeado, por ato do Magnífico Reitor da Universidade de São Paulo, o eminente Professor Miguel Reale.

Menciono todos os nomes a que até agora me referi, não só porque a eles está ligado, imediatamente, o meu destino de professor universitário, mas, também, como homenagem ao saber e à dignidade de cada um deles, exemplo que todos são de acendrado amor à causa do ensino no Brasil. Não excluo, entretanto, de iguais predicados, todos os demais mestres que, com o seu endôsso ao julgamento da douta Comissão de Concurso, deram ainda maior ênfase à minha vitória.

$\mathrm{Na}$ solenidade de hoje, tive, a mais, o privilégio de ser saudado pelo eminente Professor Sylvio Rodrigues. A ele, nome consagrado de jurista, colega de turma nesta Faculdade, o meu cordial abraço de agradecimentos pelo carinho com que a mim se referiu e pelos transbordamentos a que foi levado, por imposições do seu grande coração. Mestre dos mais eminentes, não obstante a severidade de seus julgamentos, não poderia deixar de ser condescendente para com um velho amigo. Foi ele o primeiro, da Turma de 39, a chegar a estas alturas e alegra-me tenha sido ele o intérprete da Douta Congregação, no momento em que lhe venho fazer companhia.

A Luiz Eulálio de Bueno Vidigal devo uma explicação necessária: jamais tive a veleidade de substituí-lo na regência da cadeira que tanto dignificou e da qual se afasta na plenitude de seu saber e de sua jovialíssima maturidade. O que nele mais impressiona é a sua independência total. Jurista que pensa os problemas da nossa ciência, para dar-lhe soIuções originais, marcantemente suas, é bem um exemplo de emancipação intelectual, firme nas suas concepções, rigorosamente lógico nos seus raciocínios, livre, seguro e profundamente fecundo nas suas construções, a que não falta o módulo 
do maior rigor científico e do mais adequado senso pragmático.

Se esses dotes - que marcam a sua figura ímpar de professor - agravam os meus compromissos, como seu sucessor, constituem, também, estímulo para um trabalho que sei dos mais árduos e que espero seja profícuo, na medida em que minhas forças o permitirem.

De Luiz Nicolau Fagundes Varella - avô do poeta - aos mestres de nossos dias, a cátedra de Direito Processual Civil e a regência dessa disciplina tem sido, aqui, ilustrada por nomes que perfazem uma vigilância conspícua, digna das melhores tradições de cultura desta Faculdade. Esse mais um desafio aos que ascendem à Congregação, co-responsáveis que passam a ser por um acervo de cultura que dá a medida da nossa efetiva maturidade.

Não basta, realmente, que os índices materiais assinalem um crescimento excepcional, para que excepcional seja o desenvolvimento comunitário. Na sua dimensão social, o homem pode produzir muito, sem desenvolver-se, se a sua criatividade estaca. Não raro, o trabalho que assume o caráter de tarefa e se cumpre, mecanicamente, nada significa para o aperfeiçoamento do homem que só na sua dimensão individual opera. Aí, no plano das energias criadoras de cada um é que está o verdadeiro látego do desenvolvimento. A obra que exige amor para ser realizada - que se faz a golpes de ternura - essa é a que nos engrandece, espiritualmente, tornando-nos artífices do aperfeiçoamento de nossos semelhantes. Arrefecida a força criadora - que é obra do espírito - o próprio desenvolvimento material se compromete, pela perda do impulso que só a exata inteligência de seus problemas permite manter.

Como valor espiritual, toda criatividade é, primeiro, introversão que, depois, se exterioriza, quando excede a dimensão individual do homem para projetar-se em sua dimensão 
social. A grandeza exterior depende, pois, da grandeza interior do homem. Por isso é nobre e dignificante a missão do professor que tem a tarefa de construir, interiormente, homens. Por isso a cultura - expressão do espírito humano - é o bem maior que a nós cabe preservar, para que permaneçam as notas que qualificam determinado momento histórico e assinalam o seu futuro.

A Congregação da Faculdade de Direito da Universidade de São Paulo tem sabido defender o patrimônio cultural que nos legaram as gerações passadas, pelo qual se definem as nossas perspectivas históricas. Mais do que isso, tem podido acrescentar, ao longo do tempo, engastes preciosos aos cabedais que assim recebeu e deve transmitir às gerações futuras. O lavor novo, esse não deve desfigurar a obra feita, mas amoldar-se a ela, para enriquecê-la de novos valores. Nos sítios sagrados não há lugar para iconoclastas.

Não se perca de vista que o presente nada mais é do que uma projeção do passado que arremete para o futuro. No curso que solta o tempo não há segmentos separáveis, senão na medida de nossas abstrações, dominadas pela ânsia de fixar momentos, como se fosse possível limitar o infinito. À sua medida procura o homem reduzir o imensurável, desapercebido de que a sua própria transitoriedade é a negação de si mesma, porque enovelada à trama do absoluto. A própria razão humana, vinculada à sua essência, não escapa a esse paradoxo. Daí a inconstância das posições que assume, o fluxo e o refluxo das idéias que, entretanto, vão tornando claro um sulco residual que assinala o perene que há nelas, resultante de extremos que se tocam e aí realizam síntese conciliadora.

Assim vai o homem deixando, ao longo da história, a marca fundamental do seu pensamento, o rumo de suas idéias. "As épocas velhas - escreveu Octavio PAz - nunca desaparecem completamente e todas as feridas, inclusive as mais antigas, vertem sangue" $E$ isso que nos situa individualmente, e individualmente nos marca, levando o poeta a est'outra obser- 
vação, igualmente feliz: "Quando digo primavera, tu pensas na que vistes em tua terra, certa tarde, sob uma luz prateada. E a primavera faz parte do teu ser, é uma parte da tua cultura, é isso que recordas, depois de tê-lo esquecido"

Vinculado ao meu mundo existencial, este momento é menos fruto de uma predeterminação do que das impressões que têm modelado a minha imagem afetiva. A auréola de que se cerca, em meu espírito, a figura de meu avô - velho professor da Escola Normal - a influência de minha mãe, também ela educadora - prazerosa nesse mister que ainda hoje a encanta, na saudade dos seus dias de magistério - a imponente severidade de meus professores, especialmente os que, nesta Casa, me iniciaram no culto de suas tradições e no amor ao Direito, são alguns dos elementos que compõem o fundo lírico que fez desencadear em mim o mesmo ideal que neles vi realizado.

Em minha mulher - também ela filha e neta de educadores - esse sonho encontrou um acalanto que só o amor poderia explicar, pelo muito de renúncia que significa. A ela pertence a parte mais expressiva do sacrifício que o dia de hoje de nós exigiu. Já minhas filhas, essas foram o estímulo que não me poderia faltar, para a realização desse belo sonho. Que de melhor lhes poderia eu legar, senão esta honra inigualável de pertencer à egrégia Congregação de Professores da velha Academia do Largo de São Francisco? Que de melhor me poderiam elas dar, senão o afetuoso e comovente orgulho que têm de mim?

A meu pai - presença cada vez mais vigorosa depois que de nós se apartou, na última e desalentadora ausência - devo a suave inspiração que faz forte o meu ânimo, em tantos momentos de dúvida e ansiedade.

Aos que sempre me cercaram com seu entusiasmo, no seio de minha parentela ou no círculo dos meus amigos, a todos muito devo, porque despertaram em mim o ímpeto de 
vencer. A nenhum deles esqueço, no meu profundo reconhecimento. Especialmente, dentre eles, aqueles que também já partiram, aumentando a sombra crepuscular nos horizontes da minha saudade.

Entre os heróis que sempre povoaram o mundo fantástico dos meus sonhos de enfeitiçado pela saga que envolve em mistério a crônica da Academia, estão os meus mestres da Douta Congregação. A condescendência com que, livredocente, aqui me receberam, o nobre estímulo cam que me distinguiram e a simpatia com que hoje me acolhem, tem, para mim, a mais alta e dignificante significação.

A amizade carinhosa dos meus colegas de livre-docência - plêiade valorosa de juristas em perfeito compasso com as tradições de cultura da nossa Faculdade, a que tem acrescentado uma contribuição do melhor quilate científico e uma dedicação realmente emocionante - foi, para mim, além de honra excepcional, emulação preciosa na edificação deste momento.

No corpo administrativo, desde os seus mais modestos servidores até os mais graduados, sempre encontrei a gentileza da maior atenção e dedicado apoio. Permitam-me que lhes expresse, neste momento, o meu reconhecimento, na referência especial que faço a essa chefe exemplar de todos eles que é a nobre Secretária da Faculdade, exata, prudente e serena no cumprimento de seus deveres, além de sumamente bondosa e simpática no trato com todos nós.

A todos quantos trouxeram a esta solenidade o aderêço de uma presença para mim sumamente honrosa e alentadora, o meu abraço comovido de agradecimento.

Não posso terminar sem algumas palavras de fé. Creio na beleza espiritual do homem de nossos dias, porque entendo ineliminável a sua capacidade de amar. Embora dominado pelo lógico, pelo matemático, pelo racionalmente construído e assim inclinado para a visão de uma realidade mecânicamen- 
te explicável, não é êle insensível à síntese que, no plano da matéria, retira a evidência de que também ela é expressão do Espírito que superiormente ordena e dirige o universo. Porisso somos capazes de construir o nosso mundo afetivo e ceder ao sortilégio do luar. Porisso, no enlevo de quem vive a magia dos sonhos, quando cruzo as soleiras de pedra desta Faculdade, sob o frontal que dá para o I argo de São Francisco, ainda sinto sobre mim as velhas ombreiras de taipa que abriam para o átrio antigo dos capítulos conventuais. E o fascínio de suas tradições, a velar pela imagem antiga que domina os nossos corações. No milagre da eliminação do tempo, fundem-se os fastos da Velha Academia, num turbilhão de memórias que, ora amaina na ternura lírica das serenatas, ora recrudesce na voragem dos signos de luta, para estrugir, num surrealismo de encantamento, em versos de faz um século:

A galope, a galope, oh fantasia,

Plantemos uma tenda em cada estrela! 